\title{
Leaving MySpace, joining Facebook: ‘Growing up’ on social network sites
}

\author{
Brady Robards, Griffith University
}

\section{This is a pre-print version of this article. Please contact brady.robards@griffithuni.edu.au before citing. I will forward you a post-print version.}

\begin{abstract}
In the past decade, the reach of social network sites such as MySpace and Facebook has extended to a point where for many young people, participation is now mandatory for inclusion amongst peer groups. For some of these young people, large parts of their social lives have been played out on these sites. The shift from one site (MySpace) to another (Facebook) can also be understood as marking an important change in the way young people manage their 'digital trace'. This shift corresponds with narratives in which participants signal their movement towards forms of online sociality that are concerned with their relationships with others on Facebook rather than the often introspective and performative forms of sociality emphasised on MySpace. This article examines elements of each site that participants point towards as contributing to their own shift - both in terms of their functionality and the broader social milieu in which the sites operate. More broadly, this article also considers the 'trace' that is generated by participation on these sites (creating profiles, uploading images, commenting on pages and so on) as representing a key mechanism by which young people's transition narratives can be made accessible and visible amongst their network. This article draws on research from two linked small-scale qualitative studies conducted on the Gold Coast in Australia, the first with a group of ten young people in 2007 and the second with thirty young people in 2009/2010.
\end{abstract}

Keywords: youth; social network sites; identity; narrative; rites of passage; transition.

In reflecting upon the 'trace', made when individuals use and thus produce the internet ${ }^{1}$, Bowker (2007) makes the observation that his friends and acquaintances who died before 1992 are sparsely represented online. In 1992, the first widely adopted web browser Mosaic made the internet accessible for ordinary people in an everyday context. Bowker goes on to explain that his friends who died more recently 'carry on a rich afterlife ... [they] still receive email messages; links to their website rot very slowly; their informal thoughts are often captured on list-serv archives, on comments they have left on a website' (2007: 23). What are the implications of this new 'paradigm of the trace' for young people whose social lives are mediated online?

At one level, this article works to capture a clear shift in engagement amongst young people in Australia from the once popular social network site MySpace to the now dominant 
site, Facebook in 2008. I will describe this shift from one site to another as related to 'growing up' stories or stories of transition for the young people in the qualitative study reported upon here, conducted from 2007 to 2010. At another level, this article explores the practices by which young people manage their trace on sites like MySpace and Facebook, and considers how moving between these sites and the subsequent forms of sociality these sites afford can be understood through a narrative of transition or 'growing up'. It is my central argument that learning to manage this trace in online social spaces is an important concern for the young people in this study; a concern that it is related to stories of 'growing up', transition, reflexive identity-work and the unique social conventions and affordances of different online social spaces.

The young participants in the research reported in this article are concerned more about the implications of their own trace - profiles created, comments left, pictures uploaded - in relation to questions about privacy and friendship and what it means to be them, rather than about who will be googling them after they're gone. And yet, the possibilities raised by Bowker (2007) are rendered increasingly resonant by the extent to which young people's narratives and experiences of 'growing up' are now mediated and played out online, and subsequently scrutinised. For example, in an interview with the Wall Street Journal, the then CEO of Google Eric Schmidt suggested that eventually young people will want to change their names upon reaching 'adulthood', 'in order to disown youthful hijinks stored on their friends' social media sites' (Jenkins 2010). The implication here is that all young people are engaging in these online 'hijinks', and that 'youthful hijinks' are things to be hidden or even erased. It is also implied that young people are incapable of managing this trace. While a fuller analysis of these discourses is beyond the scope of this article, Schmidt's sentiments do represent a growing concern about the notion of a digital trace, a concern which is often directed at young people's use of social network sites like MySpace and Facebook ${ }^{2}$.

\section{Mediated youth and social network sites}

As spaces in which everyday interactions are articulated, made visible, reflexively critiqued and subsequently managed, social network sites offer a new lens for insight into human behaviour. Livingstone, for instance, observes that the broad adoption of social network sites, especially amongst a 'vanguard' of young people, has meant that 'more than ever before, using media means creating as well as receiving' (2008: 394, emphasis added). Under this model of content production, social network sites, described by Bruns as spaces 
for the 'produsage of sociality' (Bruns 2008: 316), provide not only spaces in which transitional experiences are played out, but they also act as archives of these mediated experiences-as-texts. These texts - the profiles that constitute social network sites - work to represent those transitional experiences: photos of birthdays, discussions concerning relationships and current affairs, and articulations of the relationships and systems of belonging that constitute young people's narratives of transition. The social complexities and nuances of these particular profile-based social network sites are only now beginning to undergo significant theorisation that moves beyond the descriptive, although there is a deep and robust literature on the internet as a social medium more broadly.

Turkle's $(1995,2001)$ groundbreaking work did much for early scholarship on the role of the internet as a space for identity and belonging, although it is now clear that the spaces Turkle was investigating, such as MUDs (Multi-User Dungeons) are no longer the dominant spaces for social interaction online. Whereas Life on the Screen ${ }^{3}$ may have been an appropriate descriptor for Turkle's work at the time, it would now appear that life through the screen is more apt, as social lives (in which distinctions between offline and online are increasingly problematic) are being played out through new forms of media (see also Wellman \& Haythornwaite 2002). Similarly, while Rheingold's (1994) work on virtual communities set an important agenda for the research that followed, it is clear that the 'opening up' of the internet, in terms of broadening adoption and changes that allow for 'customising the internet' (Green 2010: 79), has meant that a re-positioning of research frameworks is necessary. The communities described by Rheingold developed between people who shared a common interest but who had often not met each other in-person, whereas the relationships that are mediated on social network sites like MySpace and Facebook are largely pre-existing networks formed offline and are thus locally situated (boyd \& Ellison 2008; Joinson 2008; Jones, Millermaier, Goya-Martinez \& Schuler 2008; Robards 2010; Robards \& Bennett 2011). While the early work exemplified by Turkle (1995, 2001) and Rheingold (1994) provide invaluable foundations, the questions and assumptions that drive research around sociality in online social spaces must be continually revised. With the ongoing investment of time and self into social network sites such as MySpace and Facebook, these spaces become key to any understanding of the contemporary nature of mediated youth culture, the topic of this special issue.

Since 2003 with the rise in popularity of Friendster (boyd 2007), social network sites have come to dominate internet use in terms of reach and time invested by users. Facebook now claims to have more than 800 million active members, half of which 
reportedly access the site daily (Facebook.com, 2012). As adoption and engagement with social network sites continues, participation has not only enhanced the potential for improved sociability and inclusion, but engagement has for some become mandatory: '[without Facebook] you wouldn't know what's going on with people... you'd forget about them' $\left(\right.$ Alison $\left.{ }^{4}, 19\right)$. This extract from my own research, which I will introduce in the following section, is reminiscent of the phrase often cited as contributing to early moral panics around MySpace: 'if you're not on MySpace, you don't exist' ('Sierra' in Driscoll \& Gregg 2008: 74). These sentiments characterise a period in which some young people have been engaging with social network sites for a large part of their social lives, effectively 'growing up' on social network sites. Or, rather, their experiences of growing up regardless of whether they are mediated online or offline - are often recorded online, through social network sites like MySpace and Facebook, by way of the digital trace. How do these spaces hold up as their user base grows up? Or indeed, how do they fail to retain users? What might compel young people to move from one social network site to another as they transition towards adulthood?

Surprisingly, I have found that while a clear shift between these sites can be observed within this small study and globally (Stringhini, Kruegel \& Vigna 2010: 2; Livingstone, Ólafsson \& Staksrud 2011: 3; boyd, 2011), seven of the participants in my research - five of whom were under 18 - still actively used MySpace well into 2010, contrary to the broader move towards Facebook. Why? What are the differences in the 'traces' generated on these sites? As I will explain, the participants in this study describe their own use of these sites through a discourse of transition. For example, of the seventeen participants in their 20s that had used MySpace previously, all but one variously discussed their activities on MySpace as being more 'youthful' or 'juvenile', while the younger participants still using MySpace describe an anticipation of the move to Facebook where they will be more 'grown up' - some more reluctantly than others. What makes MySpace more 'youthful' or attractive to the younger people in this study? One possible explanation is that for the seven participants in the latter group of this study who still identified as MySpace users, MySpace was described as a place just for peers whereas Facebook was (increasingly) more likely to involve familial and other 'adult' relationships. Thus, MySpace continues to offer these young people a more peer-oriented online social space for the articulation of relationships and other systems of belonging, where the performative conventions were more introspective. 
As a categorical or developmental 'stage', the concept of youth is largely untenable. The boundaries that appear to separate childhood, youth and adulthood are 'blurred, indistinct, porous and changing' (Furlong, Woodman \& Wyn 2011: 361). Instead, understanding youth as a 'social process' (Wyn \& White: 1997: 147, italics original) provides a much more viable lens through which young people's transition narratives can be understood (see also McLeod 2000). As Wyn and White (1997: 95) argue, there is often no 'definite point of arrival' in transition narratives. The process of 'becoming adult' is highly contested, multiple, non-linear, and varied, wrought by social and geographical positions. This process of transition is punctuated and shaped by 'critical moments' (Thomson, Bell, Holland, Henderson, McGrellis \& Sharpe 2002) such as moving out of home, dropping out of school, entering a relationship, learning to drive, a death in the family, going clubbing for the first time, and so on. In Giddens' terms, the 'fateful moment' (from which Thomson et al. borrow in conceptualising the critical moment), is 'highly consequential for a person's destiny' (1991: 121), and should be understood as distinct from but certainly affecting the inconsequential goings-on of daily life. When these critical moments are articulated and made visible on social network sites, they become key markers in a mediated growing up story for young people.

Livingstone (2002: 4) points towards the central role of new media for young people who are 'motivated to construct identities, to forge new social groupings, and to negotiate alternatives to given cultural meanings'. Sharing, discussing, and remembering these critical moments becomes an important activity on social network sites, punctuating - as with offline experiences of growing up - the more mundane, everyday experiences of life that often attract criticism and derision when mediated online. For the remainder of this article, I seek to draw out the complexity inherent in social interaction on sites like MySpace and Facebook as spaces of transition and reflexivity. While the social conventions that govern these sites differ, the extent to which they make visible and archive transitional experiences - both fateful/critical and inconsequential/mundane - are key. It is my contention that these sites serve as spaces in which young people are able to undertake and articulate not only a social experience of transition with others, but also with themselves; 'a self-conscious conversation of self with self' (Henderson, Holland, McGrellis, Sharpe \& Thomson 2007: 24). 
Pre-print version: Robards, B. (2012) "Leaving MySpace, joining Facebook: Growing up on social network sites in Australia", Continuum, 26(3): 385-398.

\section{Research Methodology}

This article draws on a two-part qualitative research project involving a small group of forty young users of social network sites MySpace and Facebook in Australia. The first part of the study was conducted in 2007 with ten MySpace users aged 18 to 24 . The second part of the study was conducted over 2009 and 2010, with a slightly larger group of thirty new participants aged 15 to 27 who used a mixture of MySpace and Facebook as the latter had become the dominant social network site since the initial component of the research. In both parts of the study, research was conducted using two methods. The first was a discourse analysis of profiles, attending to profile construction and content (display pictures, autobiographical 'about me' writing, lists of hobbies and interests), articulations of social capital (Friends lists, 'top friends', quantity of Friends ${ }^{5}$ ) and other semiotic events (status updates, blog/note entries, shared content such as links and videos). These discourse analyses sought to capture a sense of the trace these profiles created, and how that trace was managed. Each profile proved to be rich with symbolism and self-narrative devices, although the true resonance of these observations only emerged through the second research method: semi-structured, in-person, in-depth interviews with participants. The discourse analysis of profiles informed the interviews themselves, such that participants were able to both describe their own practices and also (through prompts from my prior analysis) comment reflexively on elements of their profile they may have otherwise avoided or considered irrelevant. For example, participants would easily engage in story-telling around initial adoption of a social network site or describe Friending ${ }^{6}$ strategies (Robards 2010), but were often not able to (or hesitant to) recall specific images on their profile or affiliations such as groups, interests or 'liked' pages. Thus, coupling the analysis of profiles with in-depth interviews allowed for the discourse analysis to be verified while also adding a greater potential for probing in the interviews themselves. As part of the ethical consideration of the research ${ }^{7}$, only information gathered from the in-person interviews is quoted here.

Participants were recruited through an opportunistic process of selective snowballing, beginning with coursework students at a Gold Coast ${ }^{8}$ university from programs including journalism, engineering, public relations, psychology, sociology, nursing and creative arts. Subsequent participants were then selected with the intention of diversifying the sample, focussing primarily on individuals with non-tertiary educational backgrounds, including younger (15- to 17-year old) participants. This selective snowballing resulted in a group of participants aged 15 to 27 , including 24 females and 16 males. Nine of the participants had 
no tertiary background. Many of the university students interviewed also undertook casual, part-time or full-time work. Occupations of participants including military work, real estate, hospitality, retail, childcare and finance. Three participants were international students (from Canada, Malaysia and Denmark), while the remaining thirty-seven participants identified as Australian. The single commonality between all participants was that they were residing on the Gold Coast and that they were users of either Facebook or MySpace. Beyond these markers, there was no direct testing for income, ethnicity or first language. While these considerations were beyond the scope of this research project, they are important areas for future research in this emerging area (see, for example, Nakamura \& Chow-White 2011).

\section{Leaving MySpace, joining Facebook: functionality and critical mass}

I used to [use MySpace more], because I had more friends on it. Then everyone went to Facebook. So I moved to Facebook.

('Adam', 16)

[Facebook] does have more of a buzz. It feels like there is stuff happening all of the time. And even though I'm not interested in that stuff, it's kind of addictive in a way... people post all these sort of vague, ambiguous statements about their life and I'm like "alright I'll buy it!"

('Shannon', 23)

Before I can properly discuss the discourses of transition that are enabled by and played out on these sites, a more rudimentary discussion of the motivations for engaging with one site over another, and a brief history of the move from MySpace to Facebook is necessary. In 2008, a shift in usage occurred amongst young Australian users of social network sites (Young 2009: 40). This shift was between the once popular MySpace towards the now dominant Facebook. By June in 2008, MySpace had clearly lost its ground to Facebook in terms of its Australian audience, such that by August, Facebook was the fourth most popular online destination in Australia, with MySpace at seventh (Hitwise.com 2008). At this point, the combined reach of these sites accounted for $4.2 \%$ of all Australian internet traffic (ibid). This shift was by no means overnight, nor was it unique to Australia. Elsewhere, such as in the U.S., the shift from MySpace to Facebook was more gradual and occurred slightly later, in the first half of 2009 (Quantcast.com 2010). In late 2010, MySpace continued to be a somewhat popular social network site in places such as the U.S. and Mexico, appearing in the top twenty websites for these countries, but had fallen into relative obscurity for 
mainstream Australian users at position forty-seven (Alexa.com 2010). At the time of publication, it is unlikely that MySpace will appear in the top 100 websites in any country. In terms of user-base, MySpace moved from a global reach of $6 \%$ of all internet users in late 2009 , down to $2 \%$ in late 2010 , to below $1 \%$ in 2011 . Facebook's global reach, on the other hand, went from $11 \%$ in late 2009 to $38 \%$ in late 2010 , and was steady at $43 \%$ in early 2012 at the last edit of this article (Alexa.com 2012). In Australia, Facebook alone now accounts for $8.02 \%$ of all national internet traffic (Hitwise.com 2012).

Interviewees reported a variety of differences between the sites. In the 2007 component of the study, Facebook was not mentioned by any of the ten participants, as it had not been widely adopted in Australia at this point. In the 2009/2010 component with thirty new participants however, in line with the shift described above, Facebook was described by each participant in ascendant terms, and was clearly the most popular site amongst this second group. Only seven of the thirty participants in the latter component of the study identified predominantly as MySpace users, although even amongst these participants, adopting Facebook was described as inevitable. That is, they would eventually 'have' to use Facebook more to stay in touch with their friends. Shannon (23), Tim (18), Jonas (17), Adam (16), Kath (16), Silvia (15) and Simon (15), identified themselves as predominantly using MySpace although each of them also had a Facebook profile, motivated by a desire to avoid 'losing touch' with friends or to keep from being left 'out of the loop'. Jonas, Kath, and Silvia described a more imminent shift to Facebook, whereas Shannon, Tim, Adam and Simon were more reluctant about the move, but still expected to be using Facebook more than MySpace in the future. Emma (20) reported using both sites equally but for slightly different purposes. She used her MySpace profile to catalogue and promote her indie music podcast but preferred Facebook to remain in touch with 'real friends'. Other participants also mentioned music as a recurring motivation for continuing to use MySpace (as its original success came from early adoption by bands), while primarily using Facebook for social communication. None of the participants in the 2009/2010 group who had used MySpace previously reported officially closing or deleting their MySpace profiles, despite not having used the service for months or even years.

The shift from MySpace to Facebook reported by the participants in this study can be attributed to two broad dimensions: functionality and critical mass. There are myriad dimensions which may contribute to leaving one site for another, or opting out of profile based social network sites more generally, although the latter was not reported by any participants in this study. These two dimensions - functionality and critical mass - also 
inform and reinforce each other. For example, a site becomes more functional (or its functions gain currency) when more of an individual's peer group use it, thus enabling and encouraging the user to continue to engage with the site. Similarly, as a site's functionality improves (or when a set of functions appear to be more appealing), a greater user base is attracted to the site.

\section{Functionality}

The design of a site, or the way a site functioned, understandably emerged as a common theme when participants were asked about motivations for using one site over another. Tim, for example, an 18 year-old born in Sydney who had recently moved to the Gold Coast to study, had tried out Facebook but was deterred by its functionality:

I actually hate how Facebook has got all those little annoying group invitations and things and it's just too much going on... pointless information. Like people just going 'oh, I'm hungry' and posting that. MySpace is a bit more like... to the point.

In other words, Facebook's functionality invites users to articulate the more mundane, inconsequential goings-on of everyday life, whereas MySpace was more highly curated. Debra (21), who used Facebook more than MySpace but still maintained her MySpace profile, also commented on the more precise, 'to the point' nature of MySpace. Comparing MySpace with Facebook, she explains that 'MySpace is a lot more... "this is who I am". It's a lot more your own side'. Both Tim and Debra are pointing to a clear difference between the two sites. MySpace, the earlier of the sites, is focussed more on the user's self-narrative as constructed through images and autobiographical text. The form and function of MySpace in this context is reminiscent of the homepage theorised in earlier internet studies literature. Cheung (2004), describes the personal homepage as being both performative ('this is me!' in Cheung's words, strikingly similar to Debra's words above) and reflexive ('who am I?'). The main social elements of the MySpace profile such as comments and the 'top friends' feature operate alongside a narrative of performative reflexivity. Facebook, on the other hand, has the social element - the dynamic social news feed - at the core of its functionality, whereas the autobiographical detail, including lists of favourite bands, books and television shows are often forgotten about. 
While all participants reported completing autobiographical 'about me' sections initially, the extent to which these were maintained varied. Lynne (24), for example, from the earlier 2007 cohort of entirely MySpace users, updated her profile picture multiple times each day to reflect her mood. While not concerned with updating her profile as regularly as Lynne, Alicia (21), another MySpace user from the earlier sample, was critical of the focus on the autobiographical on MySpace. She disliked the 'blatantly' performative nature of many MySpace profiles: 'I hate it how it's so, "this is me!"' Instead, she preferred to use song lyrics in her 'about me' section, which she changed regularly, to create a more subtle narrative of self, avoiding more overt autobiographical ("this is me!") content. In contrast, for the later 2009/2010 sample of predominantly Facebook users, updating profile information such as interests, favourite quotes, films, and books appeared to be a much lower priority. Melissa (20) explains that although she uses Facebook daily and sees it as an important social utility, she has not updated her core profile information since creating the account several years prior: 'it's not important to me... meet me and ask me, don't see that I'm a person on Facebook'. Similarly, Julie (22), Catherine (20), Naomi (19), and David (23) reported regularly making 'status updates'9 but left the more core autobiographical information unchanged (or blank) since initially signing up. Each of these participants could not recall basic autobiographical information on their Facebook profiles without a prompt, but could recall a recent status update without difficulty.

While social interactions on Facebook have previously been described largely as asynchronous (Hull, Lipford \& Latulipe 2010: 6-11; Quan-Haase \& Young 2010: 358), participants in this study have described their social interactions on Facebook as often synchronous or 'real-time' at certain times during the day. Julie (22), Brad (20), Charlotte (19), and Kath (16) described the afternoons and evenings as a busy time where many of their Friends would be active on Facebook. Charlotte specifically mentioned that she would tend to spend more time on Facebook between 4PM and 9PM, interacting with friends via IM (Instant Messenger) or comment threads (on status updates, pictures, or other posts). At other times, Charlotte explained that 'usually people aren't on then, so I don't go on then'. Brad described synchronous chats that would last between thirty minutes and two hours in the evenings. While MySpace and Facebook both offer synchronous and asynchronous functionality (boyd 2008: 44), it is clear that the kinds of interaction occurring on MySpace tend 
towards the asynchronous forms, whereas Facebook's functionality and the conventions that shape interaction on Facebook, allows for a greater level of synchronous interaction (see also Hogan 2010 and Latzko-Toth 2010). Thus, it is clear that the manifestation of the 'digital trace' differs between sites, based on temporality, functional affordances, and conventions of usage in each space.

In summary, MySpace's functionality is built around the user's self-narrative, which appears to be predominantly introspective, whereas Facebook's core functionality works to generate an inherently social, and dynamic experience where users are often engaging with each other in real-time through IM and by participating in commentary threads on photographs, status updates and so on. These differences in functionality subsequently render these sites as spatially different, with MySpace being more closely aligned with Cheung's (2004) performative model of the personal homepage and Facebook tending more towards a synchronous (Fuchs 2009: 6) social space where biographical details are less important than regular interactions. These differences in functionality and the social conventions of the digital trace have important implications for the ways in which transitional experiences - whether critical or mundane - are mediated online.

\section{Critical Mass}

While comments on the functional differences between MySpace and Facebook were common when participants were asked about why they preferred or used one site over another, it quickly became apparent that there was a second motivation for adopting a social network site or moving to another: the presence of peers. Adam (16) explains it most clearly: 'I used to [use MySpace more], because I had more friends on it. Then everyone went to Facebook. So I moved to Facebook'. While the way the site functions and subsequently the spatial experience it creates is an important part of the equation, Facebook's features are empty without a network with which to share and engage. It is, after all, the network that populates the user's news feed and comments on the user's activities. Simon (15) explains: 'I get more comments and stuff on MySpace and going onto Facebook and seeing nothing there is disappointing'. Given that users of both MySpace and Facebook connect with and Friend mainly people they already know offline (boyd \& Ellison 2008; Robards 2010), without a critical mass of known contacts on a particular social network site, its functions have no utility. 
To return to Tim (18), who initially explained that the easy-to-use functionality of MySpace is what kept him there, the full story became clearer as the interview progressed. When probed about his actual practices on MySpace, Tim explained that mainly he was just keeping in touch and up-to-date with friends and family from his hometown who he no longer saw frequently. Should they move to Facebook, he indicated that he would also be likely to make the move, despite his grievances with 'pointless information' people seemed to post on Facebook. Indeed, Tim had already begun to spend some time on Facebook to keep in touch with his family who didn't use MySpace, albeit with some resistance. He still saw himself as a dedicated MySpace user, because this was how his peer group in Sydney also identified.

Another common theme that emerged from the stories participants told about adopting MySpace or Facebook was that other people specifically encouraged them to sign-up. For some, friends or family actually created their profiles for them to begin with. Julie (22) explains that she began using Facebook after a friend of hers returned from Canada, where the site was used more widely, and convinced her to try it out. For Debra (21) it was her mother who initially encouraged her to register with Facebook so they could 'stay in touch' more easily. For Tim (18) and Simon (15), the critical mass of their networks were still predominantly using MySpace and thus the motivation to leave MySpace and join Facebook was reduced. As I will discuss in the next section, these motivations for a shift from one site to another are often reflexively linked to stories of transition or 'growing up', as young people reflect upon the nature of these spaces.

\section{Transition narratives: MySpace is for 'young people', Facebook is for 'adults'?}

While the shift from one site to another raises important questions about the differences between these sites and indeed motivating factors for such a movement, there are also broader implications and complexities underpinning the ways in which this shift is described by users of these sites. Specifically, the 'introspective', 'about me', and 'to the point' characteristics discussed above that make MySpace unique can also be retrospectively framed as 'juvenile' (Charlotte, 19). This association between MySpace and 'youth' has clear links to the previous discussion on functionality and critical mass. Similarly, current MySpace users often refer to the inevitability of moving to Facebook, as it is framed as a more 'adult' (Simon, 15) service. It is my argument that this discursive framing of these sites is linked to their format and functionality. Where MySpace foregrounded features that 
allowed the profile creator to construct a clear narrative of identity, such as a performance of self through highly curated images (Sessions 2009) and autobiographical writing (Peeters 2007), Facebook's features are more clearly oriented towards actual dynamic, synchronous (Fuchs 2009: 6) social exchanges, as discussed above.

Simon (15), the youngest participant in the study, was also the most specific in his understanding of the move from MySpace to Facebook as a 'rite of passage'. While he described himself as mainly a MySpace user, he also acknowledged that when he 'grew up' he would probably have to start using Facebook because, according to him, that's simply what you do. Other participants provided more nuanced narratives of transition around engagement with social network sites. Dora (24), for example, started using MySpace when she was on a study exchange in America. While she still sometimes uses the site to maintain contact with her American friends, she predominantly used Facebook at the time of the interview. Dora consistently referred to her time on MySpace as an 'American phase'; a phase she went through and has now moved beyond.

In the earlier 2007 component of the study on MySpace, the theme of parental involvement in social network sites did not emerge. In the 2009/2010 component of the study, however, the prospect of participants having to negotiate familial and other adult relationships on Facebook emerged more clearly. Sharon (17) started using MySpace when she was 14, but moved on to Facebook when she was 16. She had more Friends on MySpace, but Facebook allowed her to keep in touch with family too; an advantage that Sharon found herself appreciating more as she got older. Claire (25) specifically mentioned the importance of Facebook for staying in regular contact with her grandfather in New Zealand. Sharon's and Claire's experiences are consistent with findings in the longitudinal qualitative study by Henderson et al. who argue that young people develop an appreciation for home and the family as an 'emotional resource' (2007: 125) as they undergo the transition towards adulthood.

Not all participants were as positive about the presence of family on social network sites as Sharon (17) and Claire (25). Charlotte (19), for example, described a sense of dread at the thought of her parents joining Facebook and adding her as a Friend. While it hadn't happened to her yet, she had friends who had found themselves in such a situation and subsequently altered their strategies of 'impression management' (boyd 2006) or 'reputation management' (Madden \& Smith 2010). Charlotte also felt a certain pressure to not tag her friends who had parents on Facebook in any photos that may be considered, in her terms, 'risqué'; mainly, photos involving drinking and partying. Charlotte's experience 
aligns more closely with the findings of West, Lewis and Currie (2009: 620) who found in their UK study of young Facebook users a great hesitancy to allow parents access to their profiles.

While it is not my intention to necessarily frame an appreciation of or a desire to engage (or not to engage) with family or adults as a marker of transition for young people, I would argue that the presence of these sentiments in the context of social network sites does represent a shift in the conceptualisation of these spaces away from being uniquely for young people. This shift occurs primarily through, or at least is more pronounced on Facebook and thus, for the participants in this study, Facebook is rendered more 'adult' than MySpace. As Mesch and Talmud (2010: 31) explain, the 'generational divide' between young people and older family members (parents, aunties and uncles, grandparents and so on) has closed significantly since the early stages of what they term 'ICT domestication'. Similarly, Gregg (2011) describes the increasingly mundane or everyday nature of Facebook; a 'status' that MySpace didn't appear to achieve as it was adopted by a smaller and often younger demographic in Australia (Young 2009: 45). The timing of Facebook's widespread adoption and the functionality of the site as discussed in the previous section has meant that Facebook's appeal is much wider than MySpace, and thus young people are forced to negotiate the presence of older family members on Facebook. The example of those five younger (15 - 17 year old) participants who continued to engage with MySpace in 2010, despite its broader status as passé, demonstrates that this site continues to be valuable for some of these young people precisely because it is not frequented by older relatives and other adult figures in their lives. Its relative obscurity (compared to Facebook) makes it a social space free of the familial gaze where young people are free to engage with peers without parental supervision.

\section{Conclusion: Transition traces}

While leaving MySpace and joining Facebook may not in itself be as critical a transition as other rites of passage - such as coming out, participating in a religious ceremony for the first time or leaving home - it is a transition that young people do clearly invest in. Adopting and moving between forms of online sociality, such as those offered by social network sites, is a complex process that the young people in this study are negotiating in strategic, nuanced, and often very different ways that contribute to reflexive biographies of transition that scholarship in this area is only now beginning to attend to. 
The more important implication here is the observation that these sites are not only spaces in which young people can form and perform a sense of self and belonging through socialisation and communication, but they also act as spaces of reflexivity where narratives of transition are performed, commented upon, recorded and archived: the digital trace of transition. Sometimes this trace manifests in a positive form, as when Brad (20) used Facebook to look for roommates, enabling him to move out of home or when Cody (21) was able to use Facebook to communicate with his boyfriend without what he felt was the financial burden of paying for phone calls and text messages. The trace can also manifest in potentially negative forms, such as the consternation articulated by Charlotte (19) over the thought of future employers finding photos of her posted by her friend in alcohol-fuelled, compromising scenarios (see also Brown \& Gregg 2012 in this issue for a critical analysis of the discourses that shape this anxiety). While it is the latter that often attracts the most attention, framed as youthful 'hijinks' (Schmidt in Jenkins 2010) to be hidden or erased, all of these experiences contribute to the narrative of transition these sites make visible. Moving out of home, forming romantic relationships and entering into leisure practices involving alcohol can be framed as critical (Thomson et al. 2002) or fateful (Giddens 1991) moments which shape and punctuate young people's transition narratives. While the move from MySpace to Facebook may not represent a critical moment in itself, this transition does represent a shift in the way young people engage with and make visible their own transition narratives.

The transition stories that this study documents are complex and varied. Many of the stories uncovered in this research are not so much about 'growing up' as they are about troubling, complicating and reconfiguring that story. Understanding and framing youth as a process of transition, as a process of 'inventing adulthoods' (Henderson et al. 2007), which each participant understood and experienced differently, also meant leaving behind assumptions about which sites were 'in' and which sites were 'out'. It is clear that while there are visible trends in terms of reach and popularity for particular sites, qualitative investigations of the everyday experiences of young people that use these sites can make visible a series of interesting and still emerging practices and knowledges that counter these broader shifts.

\section{Acknowledgements}

I would like to thank the two anonymous reviewers for their close readings of earlier and revised copies of this article. Their feedback was immensely helpful. I would also like to 
thank Prof. Andy Bennett, co-editor of this special issue, for his guidance and advice. Finally, this article would not be possible without the time and insights of the participants who contributed to this research. These are the young people whose voices this article seeks to raise.

\section{Notes}

1. I borrow here from Wakeford's conceptualisation of websites as 'simultaneously computer code, cultural representations and the outcome of skilled labour [... they are] complex artefacts that can be written, read, used or consumed' (2004: 35).

2. See also articles by Brown \& Gregg (2012) and Dobson (2012) in this special issue, both of which attend to discourses that shape young people's engagements with MySpace (for Dobson, in relation to the construction of femininity) and Facebook (for Brown and Gregg who are concerned with discourses of regret associated with young women and their drinking practices, mediated online).

3. Life on the Screen was the name of Sherry Turkle's 1995 book.

4. The anonymity of all participants has been preserved throughout the research, and in this article interviewees have been assigned aliases. The numbers in brackets after each participant alias indicate age.

5. Consistent with boyd (2007), I capitalise the term Friend here to describe the category used on social network sites that collapses various social relationships such as family, colleagues and the more traditional notion of friend.

6. 'Friending' is a term used to describe the process of articulating a social tie between social network sites; either 'accepting' or 'rejecting' a Friendship request from another user or initiating such a request.

7. The decision to explicitly quote material only from in-person interviews was made in conjunction with participants to draw clearer boundaries around the 'material' of the research. While most participants did 'Friend' me on Facebook and/or MySpace, and while observations of online exchanges and semiotic events informed the physical in-person interviews (and were sometimes brought in to the interview), I have made the decision not to publish quotes or screen captures from the actual profiles of my participants, to better respect their privacy and anonymity. See Robards (2012, forthcoming) for a fuller account of the ethical challenges of research involving social network sites.

8. Both a region in South East Queensland on the mid-east coast of Australia and also classified as a city, the Gold Coast is perhaps best known as a tourism destination coupled with a recent and strong surge of local development - in the order of a 3.5 percent increase in population each year since the early 1990s (KPMG and University of Queensland in Wise, 2006: 177). The Gold Coast is a city with a largely transient population oriented towards construction and service industries. The city has no discernable 'centre' and it lacks a coherent narrative of place (Ditton 2010). Within the national discourse, the Gold Coast is often framed as a place that 'others come to enjoy, and leave' (Wise \& Breen 2004: 164).

9. Status updates - a core functionality of Facebook that MySpace implemented only after Facebook's success - are usually single sentences or phrases such as 'Jane is at the bank' or 'John is confused about why only half of his students submitted their essays on time'. Friends of the user can then comment 
on (or 'like') the status update. This functionality works to reinforce the social focus of Facebook, framing the space as dynamic and synchronous.

\section{Notes on contributor}

Brady Robards is an Associate Lecturer in sociology and a PhD candidate at Griffith University. His research explores how young people use online social spaces to construct a reflexive sense of identity, with a particular focus on how identities are positioned within, across or in-between systems of belonging. His work has appeared in Sociology, the International Journal for Educational Integrity, and PRism. He is the co-author (with John Carl, Sarah Baker, John Scott, Wendy Hillman, and Geoffrey Lawrence) of Think Sociology (Pearson, 2012).

\section{References}

Alexa.com. 2012. MySpace.com site info. Accessed December 6, 2009; November 11, 2010; January 13, 2012: http://www.alexa.com/siteinfo/myspace.com

Bowker, Geoffrey C. 2007. The past and the internet. In Structures of participation in digital culture, ed. Joe Karaganis, 20-36, New York: Columbia University Press.

boyd, danah. 2006. Friends, Friendsters and MySpace top 8: Writing community into being on social network sites. First Monday 11, no. 12: http://firstmonday.org/htbin/cgiwrap/bin/ojs/index.php/fm/article/view/1418/1336. boyd, danah. 2007. None of this is real: identity and participation in Friendster. In Structures of participation in digital culture, ed. Joe Karaganis, 132-158, New York: Columbia University Press.

boyd, danah. 2008. Taken out of context: American teen sociality in networked publics. PhD Thesis, University of California. Retrieved January 19, 2009: http://www.danah.org/papers/TakenOutOfContext.pdf boyd, danah. 2011. White Flight in Networked Publics? How Race and Class Shaped American Teen Engagement with MySpace and Facebook. In Race After the Internet, eds Lisa Nakamura and Peter Chow-White, 203-222, New York: Routledge. boyd, danah, and Ellison, Nicole. 2008. Social network sites: Definition, history, and scholarship. Journal of Computer-Mediated Communication 13, no. 1: 210-230.

Brown, Melissa, and Gregg, Melissa. 2012. The pedagogy of regret: Facebook, binge drinking and young women. Continuum: Journal of Media \& Cultural Studies 26, no. 3: this issue. 
Bruns, Axel. 2008. Blogs, Wikipedia, Second Life, and Beyond: From Production to Produsage. New York: Peter Lang.

Cheung, Charles. 2004. Identity construction and self-presentation on personal homepages: Emancipatory potentials and reality constraints, Web.Studies: Rewriting media studies for the digital age, eds David Gauntlett and Ross Horsley. New York: Edward Arnold.

Ditton, Shanene. 2010. Realigning community, culture and development in dispersed urban settings. Local-Global Conference Proceedings, Sept. 2 - 4, Melbourne: 164 - 182.

Dobson, Amy. 2012. 'Individuality is everything': 'autonomous' femininity in MySpace mottos and self-descriptions. Continuum: Journal of Media \& Cultural Studies 26, no. 3: this issue.

Driscoll, Catherine, and Gregg, Melissa. 2008. Broadcasting yourself: Moral panic, youth culture and internet studies. In Youth and Media in the Asia-Pacific Region, eds Usha M. Rodrigues and Belinda Smaill. Newcastle UK: Cambridge Scholars Press.

Facebook. 2012. Facebook press room, accessed August 23, 2011; January 20, 2012: http://www.facebook.com/press/info.php?statistics.

Fuchs, Christian. 2009. Social Networking Sites and the Surveillance Society: A critical case study of the usage of studiVZ, Facebook, and MySpace by students in Salzburg in the context of electronic surveillance. Salzburg: Forschungsgruppe "Unified Theory of Information".

Giddens, Anthony. 1991. Modernity and Self Identity: Self and Society in the Late Modern Age. Cambridge: Polity Press.

Green, Leila. 2010. The Internet: An introduction to New Media. Oxford: Berg.

Gregg, Melissa. 2011. Work's Intimacy. Sydney: Polity Press.

Henderson, Sheila, Holland, Janet, McGrellis, Sheena, Sharpe, Sue, and Thomson, Rachel. 2007. Inventing Adulthoods: A biographical approach to youth transitions. London: SAGE. Hogan, Bernie. 2010. The presentation of self in the age of social media: Distinguishing performances and exhibitions online. Bulletin of Science, Technology \& Society 30, no. 6: $377-386$.

Hitwise Australia. 2008. Top websites and search engine analysis report, accessed June 2, and August 3, 2008; January 13, 2012: http://www.hitwise.com/au/datacentre/main/dashboard-1706.html Hull, Gordon, Lipford, Heather Richter, and Latulipe, Celine. 2010. Contextual gaps: Privacy issues on Facebook. Ethics and Information Technology 13, no. 4: 389-302 
Jenkins, Holman W. 2010. Google and the search for the future. The Wall Street Journal. Accessed January 31, 2011:

http://online.wsj.com/article/SB10001424052748704901104575423294099527212.html Joinson, Adam. 2008. "Looking at", "looking up" or "keeping up with" people? Motives and uses of Facebook. Computer-Human-Interaction Conference Proceedings: 1027-1036. Jones, Steve, Millermaier, Sarah, Goya-Martinez, Mariana, and Schuler, Jessica. 2008. Whose space is MySpace? A content analysis of MySpace profiles. First Monday 13, no. 9: http://firstmonday.org/htbin/cgiwrap/bin/ojs/index.php/fm/article/view/2202/2024. Latzko-Toth, Guillaume. 2010. Metaphors of synchrony: Emergence and differentiation of online chat devices. Bulletin of Science, Technology \& Society 30, no. 5: 362-374.

Livingstone, Sonia. 2002. Young people and new media. London: Sage.

Livingstone, Sonia. 2008. Taking risky opportunities in youthful content creation: teenagers' use of social networking sites for intimacy, privacy and self-expression. New Media \& Society 10, no. 3: 393-411.

Livingstone, Sonia, Ólafsson, Kjartan, and Staksrud, Elisabeth. 2011. Social Networking, Age and Privacy. EU Kids Online Report: www2.Ise.ac.uk/media@lse/research/eukidsonline/shortsns.pdf.

Madden, Mary, and Smith, Aaron. 2010. Reputation management and social media: How people monitor their identity and search for others online. Pew Internet Report: http://www.pewinternet.org/Reports/2010/Reputation-Management.aspx?r=1 McLeod, Julie. 2000. Metaphors of the Self: Searching for young people's identity through interviews. In Researching Youth, eds Julie McLeod and Karen Malone, 45-58. Hobart: Australian Clearinghouse for Youth Studies.

Mesch, Gustavo S., and Talmud, Ilan. 2010. Wired Youth: The social world of adolescence in the Information Age. London: Routledge.

Nakamura, Lisa \& Chow-White, Peter (2011) Race After the Internet, Routledge: New York. Peeters, Heidi. 2007. The Networked Self: Autofiction on MySpace. Image \& Narrative 8, no. 2: http://www.imageandnarrative.be/inarchive/autofiction/peeters.htm Quan-Haase, Anabel, and Young, Alyson. 2010. Uses and gratifications of social media: A comparison of Facebook and Instant Messaging. Bulletin of Science, Technology \& Society 30, no. 5: 350-361.

Quantcast.com. 2010. MySpace.com - Quantcast audience profile, accessed November 2, 2010: http://www.quantcast.com/myspace.com.

Rheingold, Howard. 1994. The virtual community: Surfing the internet. London: Minerva. 
Robards, Brady. 2010. Randoms in my bedroom: Negotiating privacy and unsolicited contact on social network sites. Prism 7, no. 3:

http://www.prismjournal.org/fileadmin/Social media/Robards.pdf.

Robards, Brady. 2012, forthcoming. Friending Participants: Managing the researcherparticipant relationship on social network sites, Young: Nordic journal of youth research.

Robards, Brady, and Bennett, Andy. 2011. MyTribe: Postsubcultural manifestations of belonging on social network sites. Sociology 45, no. 2: 303-317.

Sessions, Lauren. 2009. 'You looked better on MySpace': Deception and authenticity on Web 2.0. First Monday 17, no. 7:

http://firstmonday.org/htbin/cgiwrap/bin/ojs/index.php/fm/article/view/2539/2242

Stringhini, Gianluca, Kruegel, Christopher, and Vigna, Giovanni. 2010. Detecting spammers on social networks. Proceedings from the $26^{\text {th }}$ International Secure Systems Lab Conference, December, Austin: http://iseclab.org/papers/acsac10-socialnets.pdf

Thomson, Rachel, Bell, Robert, Holland, Janet, Henderson, Sheila, McGrellis, Sheena, and Sharpe, Sue. 2002. Critical moments: Choice, chance and opportunity in young people's narratives of transition. Sociology 36, no. 2: 335-354.

Turkle, Sherry. 1995. Life on the Screen: Identity in the Age of the Internet. New York: Simon \& Schuster.

Turkle, Sherry. 2001. Who Am We? In Reading Digital Culture, ed. David Trend. Oxford: Blackwell.

Wakeford, Nina. 2004. Developing methodological frameworks for studying the world wide web. In Web.Studies (2nd edition), eds David Gauntlett and Ross Horsley, 34-48, New York: Oxford University Press.

Wellman, Barry, and Haythornthwaite, Caroline. 2002. The internet in everyday life. Oxford: Blackwell.

West, Anne, Lewis, Jane, and Currie, Peter. 2009. Students' Facebook 'friends': Public and private spheres. Journal of Youth Studies 12, no. 6: 615-627.

Wise, Patricia, and Breen, Sally. 2004. The Concrete Corridor: Strategising impermanence in a frontier city. Media International Australia 122: 162-173.

Wise, Patricia. 2006. Australia's Gold Coast: A city producing itself. In Urban Space and Cityscapes: Perspectives from Modern and Contemporary Culture, ed. Christoph Linder. London \& New York: Routledge.

Wyn, Johanna, and White, Rob. 1997. Rethinking Youth. St. Leonards NSW: Allen \& Unwin. 
Pre-print version: Robards, B. (2012) "Leaving MySpace, joining Facebook: Growing up on social network sites in Australia", Continuum, 26(3): 385-398.

Young, Kirsty. 2009. Online Social Networking: An Australian Perspective. International Journal of Emerging Technologies and Society 7, no. 1: 39-57. 